DOI: $10.20472 /$ IAC.2018.041.002

\title{
ATHER MAQSOOD AHMED
}

School of Social Sciences and Humanities, National University of Sciences and Technology, Pakistan

SHAHZAD ALVI

School of Social Sciences and Humanities, National University of Sciences and Technology , Pakistan

FAISAL JAMIL

School of Social Sciences and Humanities, National University of Sciences and Technology , Pakistan

\section{ASSESSING THE IMPACT OF CLIMATE CHANGE ON TOTAL FACTOR PRODUCTIVITY IN DEVELOPING COUNTRIES}

\begin{abstract}
:
It is evident that higher temperature causes discomfort, fatigue, and cognitive impairment in workers and it also affects machines' performance and thus potentially decrease labor and capital productivity. However, little attention has been paid to the effects of climate change on productivity at the macro level. Given the importance of total factor productivity for long-run economic growth, this study examines the impact of climate change on total factor productivity by using the panel data from 1990-2016 of developing countries. In doing so, at first, the present study calculates the total factor productivity by using the Cobb-Douglas production function. In the second step, the study estimates the impact of climate change on total factor productivity along with other covariates such as trade openness, education, and information and communications technology. To get the precise results, this study used panel data econometric techniques such as common, random and fixed effects. Among common, random and fixed effects models; the fixed effect model is chosen as a best candidate model through appropriate model selection criteria. The results indicate that growing temperature decreases the total factor productivity while education, trade openness and information and communications technology increase total factor productivity. This study suggests that there is a need to take adaptations to overcome the problem of climatic changes on total factor productivity in the short run along with mitigation to get the sustainable economic growth in the long run.
\end{abstract}

\section{Keywords:}

Climate change; Economic growth; Total factor productivity; Cobb-Douglas production function; Mitigation; Fixed effects

JEL Classification: R11 